\title{
\#ODU2ODU: Testing the Benefits of a Partnership Between Sport Management Classrooms
}

\author{
Brendan O'Hallarn and James Strode
}

\begin{abstract}
As sport management pedagogy has evolved, an effort has been made to incorporate popular and innovative social media technologies into classroom instruction. Academic research has suggested how the technology can be utilized to provide real-world skills for students and develop proficiencies in an area where many sport management graduates find employment. Notable among the recommendations about social media use by sport management scholars is a lack of research testing the efficacy of these tools in improving curricula. The current study relied on the recommendations of Sanderson and Browning (2015) to use the social media site Twitter to create online partnerships, testing both the results of the in-class project and the perceived benefits of such an arrangement through end-of-semester surveys with student participants. While the survey data show a true partnership may be difficult to realize - particularly during a single semester - the benefits of such an assignment were clearly articulated.
\end{abstract}

Keywords: social media, technology, pedagogy

\section{Introduction}

Students' love of sport-along with growth and innovation of sport-connected careers - have helped sport management, marketing, and communications grow as academic disciplines (Atwater, Borup, Baker, \& West, 2017; Costa, 2005; Manning, Keiper, \& Jenny, 2017; Pitts, 2001). Like business education, training in sport-related academic fields requires understanding of relevant theory and applied, practical vocational training (Chalip, 2006). Many attempts to incorporate theory and practice into the sport-connected classrooms have been studied, including popular and indispensable social media platforms (Clapp, 2015; McKinney, 2015).

Brendan O'Hallaran, PhD, is a lecturer in the Department of Communication \& Theatre Arts at Old Dominion University. His research interests include the sociology of social media interactions, particularly connected to sport. Email: bohallar@odu.edu

James Strode, PhD, is an associate professor and chair of the Department of Sports Administration at Ohio University. His research interests include philanthropy in intercollegiate athletics, coaching effectiveness, and sport management pedagogy and administration. Email: strode@ohio.edu 
With the spread of social media, and its impact on the sport business landscape (Mangold \& Faulds, 2009; Williams \& Chinn, 2010), instruction has been incorporated in sport communication curriculum. It has been utilized to understand this important societal phenomenon and provide students with skills they can use to seek employment (Billings, 2012; Goodyear, Casey, \& Kirk, 2014; Masteralexis, Barr, \& Hums, 2011). In fact, Clapp (2017) suggests social media positions are a way to break into the highly competitive sport industry. Data produced by the Sports Innovation Institute at Indiana University-Purdue University Indianapolis showed that nearly $15 \%$ of the 8,100 positions available in the sport industry in North America in November 2019 were in marketing and communication fields, which included or consisted of social media responsibilities (Sports Innovation Institute, 2019).

The idea that students could, in effect, sell themselves through the personal branding social media is a concept that runs through sport, where fans (Wann, Royalty, \& Roberts, 2000) and athletes (Smith \& Sanderson, 2015) have used their public personas to gain attention and esteem. For sport communication educators, the challenge is to turn their students' affinity for social media engagement and sport into teachable tools that enhance their opportunity in the job market (Jones, Brooks, \& Mak, 2008). Given the popularity of Twitter and its correlation with the sport industry, there has been consideration given to its role in the sport communication classroom as a tool (Anderson, Swenson, \& Kinsella, 2014; Tyma \& Pickering, 2015). Sanderson and Browning (2015) suggested that Twitter can be incorporated into the classroom, through the use of a course hashtag, for live-tweeting exercises and as a tool to analyze sport media conversations.

Another potential benefit that Sanderson and Browning (2015) ascribe to the use of Twitter in the classroom is the use of the site to develop partnerships that transcend physical barriers. The study notes students can assess an organization's strengths and weaknesses, construct recommendations for how social media can be used, and analyze Twitter data to help with organizational learning. Testing that supposition is the purpose of this paper - a case study analysis of Twitter's potential to create partnerships between sport communication classrooms.

\section{The Case Study_Putting a Partnership Together}

Sanderson and Browning (2015) offer guidance to educators about using Twitter in a multi-dimensional fashion to extend the reach of sport education. The ubiquity of Twitter and the intuitive suggestions they provide indicate that Twitter provides value to classrooms in any academic domain.

This paper represents a case study analysis of the partnership-generation potential of Twitter between two classrooms. Two 2016 fall semester sport communication classes at different universities were given an open-ended 
assignment - use the social media platform Twitter to form a connection with students they never met throughout the semester. Guided by the course instructors (the authors of this article), the students, located at universities hundreds of miles apart, participated in a goodwill exchange, known as \#ODU2ODU. The hashtag, which included the acronym of both institutions (Old Dominion University and Ohio Dominican University) served as a content hub. Students in the Sport Media/Public Relations class at Old Dominion and the Sport Communications class at Ohio Dominican used the assignment hashtag to find out about their sport management colleagues in another state. They were assigned quizzes, assessed on their engagement, and delivered a presentation about what they learned through the partnership.

\section{The Assignment}

Students were tasked with forging online relationships with students at the "other" ODU. Students were assigned to reach out to students at the other institution, finding out information about that university, its athletic programs, its sport management program, and other information students wished to share. Instructions for this first-time assignment were kept deliberately open, in part to ascertain how students would interpret their charge, as well as to discourage them from having to meet a specific quota of outreach attempts. Description of the assignment is in the appendix.

\section{Learning Outcomes}

Students shared thoughts on sporting events such as the Cleveland Indians' playoff run (Ohio Dominican is located in nearby Columbus, Ohio) and the "Circle of Unity" gesture by Old Dominion football to counter negativity in society (Minium, 2016). After creating an online community through the partnership, the students made multimedia presentations to their classmates to demonstrate what they learned about the other institution. The assignment goal was a better understanding of the use of Twitter to bridge geographic and cultural differences, as well as a sense of camaraderie and goodwill with peers whom students had never met.

\section{Measuring Effectiveness}

The instructors relied on both formative and summative assessment for this assignment. While students formed contacts with students at the other ODU, the instructors occasionally guided the interactions, suggesting prompts through periodic assignments that helped students consider their engagement efforts. 
An analysis of the engagements indicated that students used the class hashtag only sparingly at first but were prompted to participate by the pressure of course deadlines-notably the end-of-semester presentation. The assignment did encourage students to use the social media site to generate content connected to sport in many ways.

At the end of the semester, instructors sought feedback from the two classes to assess the effectiveness of the assignment and seek feedback from the classes about how to make the project more student-centered. Their words about struggling with what constituted "engagement" were instructive in helping the professors modify the assignment for future semesters.

\section{Case Study Goals}

Browning and Sanderson (2015) suggested three possible benefits from using Twitter to create partnerships as a sport communication classroom assignment: (1) Students become more actively engaged in media processes; (2) Twitter transcends geographic and other barriers; and (3) Twitter enhances participation and strengthens community.

This case study sought to empirically test Sanderson and Browning's (2015) benefits of these tools in the classroom. The analysis of the success of Twitter in creating a partnership between sport communication classrooms was conducted through two metrics: 1) analysis of the content posted to the class hashtag through Twitter; and 2) a questionnaire for students at the end of the semester, where they could provide feedback about the longitudinal assignment. The goal of the project was to provide a hands-on learning opportunity for students using the vital Twitter platform in a professional manner, and to use the students' own words to assess the benefits and drawbacks of such a goodwill exchange. In analysis of the student responses, the study provides both analysis of the social media platform's strengths and weaknesses in creating pedagogical partnerships.

This study proposes two research questions; the first is divided into three parts:

RQ1-How effectively do participants in the two classes feel the assignment met the three suggested benefits of Twitter partnerships in the classroom?

RQ1a-better engaging participants in media processes;

RQ1b-helping transcend barriers; and

RQ1c-enhancing participation and strengthening community?

RQ2 - How would participants suggest the assignment be modified to make it a more engaging learning experience for students? 


\section{Review of Literature}

Estimates show more than $98 \%$ of college students are active on at least one social media platform (Griffin, 2015). Surveys suggest picture-sharing site Instagram, videoblogging site Snapchat, and Facebook are the most commonly used platforms (Knight-McCord et al., 2016; "Social media use," 2016). However, Twitter has a high appeal among sport fans (Burns, 2014), as through a live feed of comments, Twitter serves as a simultaneous shared experience with people all over the world (Harrington, Highfield, \& Bruns, 2012). It has also been explored in depth by sport scholars interested in the nexus between the passion of sport and the instantaneity of the microblogging site (Li et al., 2019; O'Hallarn et al., 2019; Yan, Pegoraro, \& Watanabe, 2018).

Social media's ability to "shrink the world" (Shirky, 2008, p. 14) is well documented. The Twitter innovation known as the hashtag creates a clickable link into a shared community of interest (Castillo, 2013). Hashtags allow users to access tweets about a particular topic or event. Hashtags' role in the development of social identity (Smith \& Smith, 2012), fanship (Blaszka, Burch, Frederick, Clavio, \& Walsh, 2012; Gibbs, O'Reilly, \& Brunette, 2014), advancement of sport organizations (Naraine \& Parent, 2016), marketing (Pegoraro et al., 2014), and activism (Hull, 2014; O'Hallarn \& Shapiro, 2014) has suggested these online interactions can aid organizations.

\section{Social Media in the Classroom}

There has been significant scholarship on incorporating social media to create an engaged, informed classroom in every academic discipline. Social media platforms are a way for students to share with classmates (Domizi, 2013; Prestridge, 2014), promote journeys of self-discovery to engage with online content (Manuel \& Schunke, 2016), and to transition the informal learning that students receive from using the platforms into academic curricula (Chen \& Bryer, 2012).

\section{Sport Management Instruction and Twitter}

In sport management curricula, Twitter has emerged as a preferred platform. Two empirical studies have collected survey data from instructors (Lebel, Danylchuk, \& Millar, 2015) and sport marketing students (Scott \& Stanway, 2015). The Lebel et al. (2015) study found enthusiasm for the platforms was also accompanied by trepidation on the part of many sport instructors, because use of the platforms represented a change to classroom management. Respondents in Scott and Stanway (2015) supported the concept of Twitter use in class but suggested further analysis of the platforms can improve their effectiveness as a teaching tool. More recently, Feito and Brown (2018) provided a roadmap for 
adopting Twitter for in-class exercises in consuming news, analysis, and writing.

The present study took a different approach. Starting with the acceptance that social media's societal penetration necessitates its inclusion in the sport communication classroom, the case study analysis of this assignment sought to figure out what was working, and what was not, with Twitter. Providing students with a deliberately open-ended assignment — and then allowing them the opportunity to assess their learning experience - can offer insight from both instructors and learners about the value of Twitter-enabled partnerships.

\section{Method}

Throughout the semester-long assignment, students were tasked with engaging on Twitter with students at the "other" ODU through interactivity, quizzes, and questions asked of the other institution. At the end of the semester, students delivered presentations, conveying what they learned about the other ODU. Following this, students were offered an opportunity to complete a qualitative survey about the class assignment. The survey was created to examine the benefit of Twitter hashtag partnerships to learning in the sport communication classroom, specifically the three benefits suggested by Sanderson and Browning (2015). The researchers sought to assess the benefits and drawbacks derived from participation in the mandatory class assignment. This study seeks to add to the body of literature refining effective sport and social media pedagogy practice.

\section{Data Collection and Procedure}

One of the many benefits of hashtags is that use of the technological affordance in a tweet can be accessed in reverse-chronological order, unlike the majority of the Twitter feed, which has employed an algorithm to curate the user experience since 2015 (Oremus, 2015). That made data collection of tweets sent using the \#ODU2ODU hashtag straightforward for users. Not all tweets sent about the assignment could be gathered by researchers, as there is no way to access a tweet a student may have deleted. Also, analysis of hashtag conversations suggests that in back-and-forth interchanges, the hashtag is frequently discarded as an unnecessary marker (Bruns, 2012), meaning those tweets would not show up in a search.

In addition, near the end of the semester, students were offered a survey through an anonymous online link, which took participants to a page in the online survey tool Qualtrics. There was no obligation for students to complete the nine-question survey. The survey, which received IRB approval, was created based on the literature about effective sport and social media pedagogy, particularly to test the assertions in Sanderson and Browning (2015) of the potential 
for online partnership creation that traverses distance through Twitter. The questions, which underwent a quality check for validity by two qualitative research experts, are listed in Table 1.

\section{Table 1. Questionnaire Given to Participants in the \#0DU20DU Classroom Study}

\section{Question}

1. What did you learn about the "other" ODU during this assignment?

2. What role did Twitter play in your online learning about the "other" ODU, and the "other" ODU sport management classroom?

3. What is your assessment of how effectively the "other" ODU uses Twitter to inform audiences about its athletic teams?

4. How effectively do you feel you engaged and connected with students at the "other" ODU during this assignment?

5. What did you learn, specifically, about being a sport management student at the "other" ODU?

6. What information did you feel like you still needed to learn about the "other" ODU following this assignment?

7. How do you feel these gaps in your knowledge about the "other" ODU are best addressed?

8. What was your favorite part of this assignment?

9. What would you change about the assignment if you could?

\section{Data Analysis}

\#ODU2ODU Tweets

Various content analytic methodologies have been employed in sport-themed research of tweets, including random-sampling coding sorting tweets into thematic categories (Blaszka et al., 2012), use of software programs like Leximancer to conduct conceptual and relational analysis between tweets (Pegoraro, Burch, Frederick, \& Vincent, 2014), and analysis of media framing of Twitter activity (Burch, Frederick, \& Pegoraro, 2015). For analysis of the tweets sent by students during the \#ODU2ODU class assignment, a manual holistic approach to content analysis was employed, coding the tweets as holistic variables manually (Matthes $\&$ Kohring, 2008). The reasons for this are two-fold: 1) The relatively modest number of tweets with the hashtag being analyzed allowed researchers the luxury of hand-coding; and 2), more pertinently, Twitter has become an increasingly multimedia-enabled platform. Students in the \#ODU2ODU goodwill exchange generated a great deal of media-rich content, from polls, to video, to memes. Therefore, it made more sense to analyze the tweets as categories of media, rather than for their thematic content. 
Following manual analysis of the tweets, the two researchers independently coded for media frames present in the classroom commentary. Following independent analysis, the researchers compared findings to reach a consensus list of media frames reflected in the Twitter activity, using the Burch et al. (2015) approach as a guide.

\section{Questionnaire Responses}

Following collection of the online questionnaires, a total of 28 participants combined provided data with an overall response rate of $63 \%$. The responses were submitted anonymously and the instructor from the other ODU conducted the primary analysis (i.e., the instructor from Ohio Dominican reviewed responses from Old Dominion, and vice versa) in an effort to bracket out the researchers' biases. Sport and social media research frequently relies on different content analysis methodologies under the umbrella of constant comparative methodology (Miles \& Huberman, 1994), utilizing the emergence of themes (Pegoraro, 2010; Sanderson \& Hambrick, 2012) or frames (Blaszka et al., 2012). The inherent identification of and attempts to bracket out bias helps insulate constant comparative methodology from the critiques that qualitative data analysis has been subject to previously (Patton, 2002).

For this study, a directed content analysis was conducted, a methodology utilized when there is prior understanding of phenomena that can be assessed through further study (Hsieh \& Shannon, 2005). The goal of a directed approach is to extend a theoretical framework or theory - in this case, the value of online partnerships to Twitter's use in the sport management classroom, namely exploring the suppositions in the Sanderson and Browning (2015) paper. Before analysis of the data was undertaken, that essay was reviewed. The analysis found three positive benefits of Twitter that can result in a Twitter partnership - (1) students can become more actively engaged in media processes; (2) Twitter helps transcend geographic and other barriers; and (3) Twitter can enhance participation and strengthen community.

Each researcher analyzed responses for emergent themes from the classroom they did not teach, then the responses were member-checked by the other researcher to confirm the findings. This is consistent with the constant comparative methodology utilized in qualitative data reduction (Hays \& Singh, 2011; Strauss $\&$ Corbin, 1994). For the analysis, each researcher read the data several times to get a sense of the dominant content and themes in the questionnaire responses (Potter \& Levine-Donnerstein, 1999). Researchers then looked for data relevant to the three proposed benefits, coding the answers positive and negative.

Next, the researchers compiled suggestions for how the assignment could be modified to make it more impactful for students. This is consistent with the 
iterative churn of pedagogy research, as new ideas are tested and then adopted, adapted, or discarded as new technology emerges (Chao, Parker, \& Fontana, 2011; McLoughlin \& Lee, 2008). The intended result from the responses from the students was twofold - an assessment of the perceived benefits of a sport communication-themed Twitter partnership, and a roadmap for improving use of the social media tools in future classrooms, thus adding to the body of knowledge of Twitter in sport communication pedagogy.

Of the $n=28$ valid responses from the survey, 15 were from Old Dominion and 13 from Ohio Dominican. Mann and Stewart (2000) suggested a byproduct of online surveys is responses tend to be briefer. For this study, the Qualtrics platform was manipulated so that the response to each question needed to be at least 140 characters to be valid. The vast majority of responses were far longer than the 140-character minimum. Only one respondent (who was not counted among the 28) simply typed random characters into space for responses on Qualtrics.

\section{Results}

\section{Empirical Assessment of \#ODU2ODU Tweets}

The first observation that is readily apparent in reviewing the nearly 400 tweets sent with the \#ODU2ODU hashtag is that some students participated far more actively than others in the exercise. One student from Ohio Dominican University sent 31 tweets during the course of the semester, whereas many students - judging by the gap between the number of unique Twitter handles and the rolls of the two classes - did not send a single tweet using the hashtag. The number of tweets is likely higher than illustrated in Twitter's archiving function, because if a user's account is set to private, their tweets do not show up in searches, and deleted tweets disappear from the website as well. There were also several invitations to continue conversations via Twitter's "direct message" function, meaning there was almost certainly more engagement than universal hashtag use demonstrated.

Analysis demonstrated that media frames reflected in the hashtagged tweets could be broken into three broad categories of engagement. The first is salutations, informal greetings between the two class cohorts. Examples include "Excited to make some new connections with "the other odu" Ohio Dominican University this semester \#ODU2ODU" and "Does Old Dominion University have any outside tenants using their facilities? Pro, semi-pro, high school, youth club sports, etc? \#ODU2ODU." This category of tweets included conversation starters and general inquiries about life on campus at the other ODU. Another media frame involved the invocation of direct solicitation of information from the other class, which included tweets sent in response to classroom assignments. 
Examples of this included "I've given out so many random facts I'm starting to run out of new ones off the top of my head, but ask me questions if you got em \#ODU2ODU" and "How's your football team looking?? \#ODU2ODU." A subcategory of solicitation utilized a technological affordance of the platform-Twitter polls. Following a poll about the anticipated USC-Alabama football game, more than a dozen Twitter polls about topical sports issues - usually the games on the field - were rolled out in short order.

The final category of tweets that emerged from the analysis is commentary by students on sport issues of the day, both on-field contests and political statements. Examples include "What do you think of the Cavs asking to move their game up to avoid conflict with the World Series tonight? Fair or unfair? \#ODU2ODU" and "Obama Backs Up Kaepernick, what do we think? \#ODU2ODU." Many of these posts included links to other media, such as news stories or videos. A few relied on other media to amplify the content of the tweet, such as GIFs or memes. Given the proliferation of meme culture on social media platforms in the second half of the just-ended decade (Grant, 2019), there would likely be more of the remixed humor media reflected in the tweets from students in the two classrooms if this project was done in 2019, instead of 2016.

\section{Assessing the Three Suggested Benefits to Twitter Partnerships}

In response to the three parts of the first research question, each of the three suggested benefits to forming Twitter partnerships was referenced abundantly in the responses of the students. Material from the survey items was found to be relevant in assessing whether the benefits of Sanderson and Browning's (2015) online partnerships were met.

\section{Students Can Become More Actively Engaged in Media Processes}

Students largely affirmed this suggested benefit of the assignment, indicating that the assignment provided a unique way to communicate, become more active on Twitter, and learn information about the other university. "It put a whole new perspective on (social media) for me in the sense of my ability to communicate information over Twitter," one Old Dominion student wrote. A student from Ohio Dominican added: "They are way more engaged in this than I thought they would be, which makes me more interested in interacting with them." Some noted the challenge in creating community using only social media. "It was eyeopening to see just how difficult it is to generate interest through a hashtag," an Ohio Dominican student said. There were also complaints about a lack of engagement by their peers at the other institution. "One of the students (w)as active on Twitter... but other than that we had to do the research ourselves," an Old Dominion student wrote. 


\section{No Restriction Because of Geographic Barriers}

The fact that this assignment could occur is a demonstration of the second benefit of Sanderson and Browning's (2015) Twitter classroom partnership—shrinking geographic barriers. The students felt the ability to bridge the two campuses was a clear positive. "University websites tell you about the institution in general, but social media gives you a look on the students and how they really are," an Ohio Dominican student wrote.

\section{Twitter Can Enhance Participation and Strengthen Community}

This was a goodwill exchange with a classroom, not a partnership with a formal sport organization, but there was still an opportunity for students to create community through the hashtag. According to their responses, by and large, they did not. "I would always use \#ODU2ODU and expect to gain some kind of responses to the tweets I put on it, but never did," an Old Dominion student wrote. The lack of engagement was disappointing to students. "It seemed like it was just basic current events," an Ohio Dominican student reported. Still, some students remarked that the requirement for engagement did cause some connections to be formed eventually. "The other kids took a while to warm up and engage with us, but when they did the project became that much easier," wrote an Old Dominion student.

\section{General Feedback About Improving the Assignment}

The first-time assignment was not perfect. Material covering suggestions for future iterations of the assignment was gleaned from the last two questions of the survey - (a) What was your favorite part of this assignment?; and (b) What would you change about the assignment if you could?

Students affirmed that the project was rewarding, interesting, and made them think about social media in new ways. In addition, students offered specific ways a social media goodwill exchange can be modified to make it a better learning experience. These included a closed group where notifications would be distributed with each interaction (an Ohio Dominican student suggestion), as well as other extrinsic motivational devices to force students to invest in the assignment. Or more regular assessments: "Have a weekly grade instead of having one large grade would encourage participants to interact more with each other and help out in the long run," an Old Dominion student wrote.

\section{Discussion}

This study sought to assess the utility of Twitter in generating a partnership between two classrooms hundreds of miles apart (Sanderson \& Browning, 2015), 
predicated on the belief that social media platforms are the media space where today's college students are most active. Because both job-seeking graduates and prospective employers are using the tools for professional development (Torres, 2019), equipping students with social media skills can help arm them for their career search. This exploratory study revealed the potential of an assignment such as a multi-class partnership, but also the limitations in such an exercise as a way for students to showcase their social media skills. Administering this assignment and analyzing its output and research findings reveals key lessons for sport and communication educators to be mindful of. They include:

1. Get a leg up: Students equipped with creative, connected social media skills can have an advantage in their career search. Since so many "first" jobs for graduates in communication and sport management are in the social media space, the modified adage "practice makes better" is applicable.

2. Twitter helps shrink the world: Twitter itself as a platform is useful for a between-classes partnership because there is no restriction placed by physical or geographic boundaries. These two classes were hundreds of miles apart, but still maintained an active communication space. Thinking of this somewhat self-evident finding through a 2020 lens, this is a rare class assignment that could continue unimpeded through the massive disruption of the COVID-19 pandemic. Indeed, students forced to social distance might be challenged to embrace such a virtual assignment with vigor, as the current burst of creativity and humanity on social media illustrates (Newton, 2020).

3. Build the brand: The researchers were surprised by the lack of initiative shown in using Twitter for this assignment. Because the principles of connection and partnership have been touted since the very beginning of social media's spread (Shirky, 2008), instructors running an assignment such as this should illustrate the clear value of the assignment for students to showcase themselves. By building their professional brand -including possibly through other social media platforms such as Facebook, Instagram, and Linkedln — students can enhance their visibility to prospective employers.

4. Show the way: The assignment was structured in an exploratory fashion so that students could tailor the interactions to their interests. However, end-of-semester surveys lamented the lack of direction for the assignment. To actively engage students in the media process, instructors should encourage mastery of the platforms through showcasing to the assignment participants examples of effective social media engagement. The entire assignment could also be organized around an appeal or cause, to provide extrinsic motivation to use Twitter to its full effect.

5. Did it work?: Assessing how closely students reflect Sanderson and Browning's (2015) three suggested benefits of online partnerships is straightforward — students became engaged in media practices (to a point); they certainly transcended physical barriers; and they didn't, in this case, go very far in creating a community. But how does one assess individual participation in such an exercise? Since volume does not equal value in social media practice, the assessment should not simply 
involve a tally of posts. Rather, assessment through online exercises, quizzes, and other activities where students can showcase engagement is a more worthwhile way to assess student learning.

6. A methodology to try: A model such as this could work in parallel classes — or even between multiple classes - in any discipline, from communication, to business, to nursing. In order to produce the most beneficial learning exercise, students need to be encouraged to move beyond their comfort zone with the platform, attempting to forge online connection through more creative expression.

\section{Conclusion}

Pedagogy's iterative nature demands that innovations be tested in the classroom and altered as necessary. If this assignment was conducted again, even by the same two classes, led by the same instructors, it would be changed demonstrably because of the information gleaned from the students' end-of-semester survey responses. Those same responses, however, indicate the promise for this assignment to demonstrate the value of social media tools for gathering information and creating community.

The researchers believe this assignment could be modified to any two (or more) sport communication classrooms, turning the attention of students beyond the physical environs of the class. In addition, it is clear that this assignment can be modified for use between any two classrooms - even at different academic levels - or between a classroom and a professional entity. The simple "pen pal" effect of making a connection with someone from far outside of a student's social circle had value. The revelations that students found interesting about their counterparts hundreds of miles away reflect both a narrow existing worldview, but also a desire to broaden it.

\section{References}

Atwater, C., Borup, J., Baker, R., \& West, R. E. (2017). Student perceptions of video communication in an online sport and recreation studies graduate course. Sport Management Education Journal, 11(1), 3-12. https://doi.org/10.1123/smej.2016-0002

Billings, A. C. (Ed.). (2012). Sports media: Transformation, integration, consumption. New York, NY: Taylor \& Francis. https://doi.org/10.4324/9780203832790

Blaszka, M., Burch, L., Frederick, E., Clavio, G., \& Walsh, P. (2012). \#WorldSeries: An empirical examination of a Twitter hashtag during a major sporting event. International Journal of Sport Communication, 5(4), 435-453. https://doi.org/10.1123/ijsc.5.4.435

Bruns, A. (2012). How long is a tweet? Mapping dynamic conversation networks on Twitter using Gawk and Gephi. Information, Communication \& Society, 15(9), 1323-1351. https://doi.org/10.1 $\underline{080 / 1369118 X .2011 .635214}$ 
Burch, L. M., Frederick, E. L., \& Pegoraro, A. (2015). Kissing in the carnage: An examination of framing on Twitter during the Vancouver riots. Journal of Broadcasting \& Electronic Media, 59(3), 399-415. https://doi.org/10.1080/08838151.2015.1054999

Burns, M. J. (2014, July 25). How Twitter is part of the 'fabric' of sports in 2014. Forbes. Retrieved from http://www.forbes.com/sites/markjburns/2014/07/25/how-twitter-is-part-of-thefabric-of-sports-in-2014/

Castillo, J. (2013, June 20). The humble history of the hashtag \#and \#why \#it \#matters. EContent. Retrieved from http://www.econtentmag.com/Articles/Column/Content-Throwdown/The-Humble-History-of-the-Hashtag-And-Why-It-Matters-90249.htm

Chalip, L. (2006). Toward a distinctive sport management discipline. Journal of Sport Management, 20(1), 1-21. https://doi.org/10.1123/jsm.20.1.1

Chao, J. T., Parker, K. R., \& Fontana, A. (2011). Developing an interactive social media based learning environment. Issues in Informing Science and Information Technology, 8, 323-334. https://doi.org/10.28945/1421

Chen, B., \& Bryer, T. (2012). Investigating instructional strategies for using social media in formal and informal learning. The International Review of Research in Open and Distributed Learning, 13(1), 87-104. https://doi.org/10.19173/irrodl.v13i1.1027

Clapp, B. (2015, June 22). The skills needed for sports marketing jobs. WorkInSports.com. Retrieved from http://www.workinsports.com/blog/sports-marketing-jobs-the-skills-you-need/

Clapp, B. (2017, July 20). Sports jobs in focus: Becoming a sports social media manager. WorkInSports.com. Retrieved from https://www.workinsports.com/blog/sports-jobs-in-focus-becoming-a-sports-social-media-coordinator/

Clavio, G. C., \& Walsh, P. (2014). Dimensions of social media utilization among college sport fans. Communication \& Sport 2(3), 261-281. https://doi.org/10.1177/2167479513480355

Costa, C. A. (2005). The status and future of sport management: A Delphi study. Journal of Sport Management, 19(2), 117-142. https://doi.org/10.1123/jsm.19.2.117

Department of Human Movement Sciences. (n.d.). Old Dominion University. Retrieved from http://catalog.odu.edu/undergraduate/dardencollegeofeducation/humanmovementsciences/\#bachelorofscienceinsportmanagementtext

Domizi, D. P. (2013). Microblogging to foster connections and community in a weekly graduate seminar course. TechTrends, 57(1), 43-51. https://doi.org/10.1007/s11528-012-0630-0

Feito, Y., \& Brown, C. (2018). A practical approach to incorporating Twitter in a college course. Advances in Physiology Education, 42(1), 152-158. https://doi.org/10.1152/advan.00166.2017

Gibbs, C., O’Reilly, N., \& Brunette, M. (2014). Professional team sport and Twitter: Gratifications sought and obtained by followers. International Journal of Sport Communication, 7(2), 188-213. https://doi.org/10.1123/IJSC.2014-0005

Glaser, B., \& Strauss, A. (1967). The discovery of grounded theory. Hawthorne, NY: Aldine.

Goodyear, V. A., Casey, A., \& Kirk, D. (2014). Tweet me, message me, like me: Using social media to facilitate pedagogical change within an emerging community of practice. Sport, Education and Society, 19(7), 927-943.

Grant, K. (2019, December 27). The decade in memes. BBC Newsbeat. Retrieved from https:// www.bbc.com/news/newsbeat-50599756

Griffin, R. (2015, August 22). Social media is changing how college students deal with mental health, for better or worse. The Huffington Post. Retrieved from http://www.huffingtonpost. com/entry/social-media-college-mental-health_us_55ae6649e4b08f57d5d28845 
Harrington, S., Highfield, T., \& Bruns, A. (2012). More than a backchannel: Twitter and television. Audience interactivity and participation, 10(1), 13-17.

Hays, D., \& Singh, A. (2011). Qualitative inquiry in clinical and educational settings. Charlottesville, VA: Wiley.

Hull, K. (2014). \#Fight4UNCWSwimandDive: A case study of how college athletes used Twitter to help save their teams. International Journal of Sport Communication, 7(4), 533-552. https://doi. org/10.1123/IJSC.2014-0030

Jobs in sport management posted on teamwork online (2019). Sports Innovation Institute. Retrieved from https://sii.iupui.edu/Research/Data-Links/index.html

Jones, D. F., Brooks, D. D., \& Mak, J. Y. (2008). Examining sport management programs in the United States. Sport Management Review, 11(1), 77-91. https://doi.org/10.1016/S1441$\underline{3523(08) 70104-9}$

Knight-McCord, J., Clearly, D., Grant, N., Herron, A., Jumbo, S., Lacey, T., Livingston, T., Robinson, S., Smith, R., \& Emanuel, R. (2016). What social media sites do college students use most? Journal of Undergraduate Ethnic Minority Psychology, 2, 21-26.

Lebel, K., Danylchuk, K., \& Millar, P. (2015). Social media as a learning tool: Sport management faculty perceptions of digital pedagogies. Sport Management Education Journal, 9(1), 39-50. https://doi.org/10.1123/smej.2014-0013

Li, B., Dittmore, S. W., Scott, O. K., Lo, W. J., \& Stokowski, S. (2019). Why we follow: Examining motivational differences in following sport organizations on Twitter and Weibo. Sport Management Review, 22(3), 335-347. https://doi.org/10.1016/j.smr.2018.04.006

Mangold, W. G., \& Faulds, D. J. (2009). Social media: The new hybrid element of the promotion mix. Business horizons, 52(4), 357-365. https://doi.org/10.1016/j.bushor.2009.03.002

Mann, C., \& Stewart, F. (2000). Internet communication and qualitative research: A handbook for researching online. Thousand Oaks, CA: Sage. https://doi.org/10.4135/9781849209281

Manning, R. D., Keiper, M. C., \& Jenny, S. E. (2017). Pedagogical innovations for the millennial sport management student: Socrative and Twitter. Sport Management Education Journal, 11(1), 45-54. https://doi.org/10.1123/smej.2016-0014

Manuel, J. T., \& P. Schunke, M. (2016). Meeting students where they are online, but leading them somewhere more interesting: Reflections on teaching the Facebook class. College Teaching, 64(3), 112-118. https://doi.org/10.1080/87567555.2015.1099094

Masteralexis, L., Barr, C., \& Hums, M. (2011). Principles and practice of sport management. Burlington, MA: Jones \& Bartlett Publishers.

Matthes, J., \& Kohring, M. (2008). The content analysis of media frames: Toward improving reliability and validity. Journal of Communication, 58(2), 258-279. https://doi.org/10.1111/j.14602466.2008.00384.X

McKinney, C. (2011, January 31). Uncovering the hidden sports job market. Sports Networker. Retrieved from http://www.sportsnetworker.com/2011/01/31/sports-job-market/

McLoughlin, C., \& Lee, M. J. (2008). Future learning landscapes: Transforming pedagogy through social software. Innovate: Journal of Online Education, 4(5), 1.

Miles, M. B., \& Huberman, A. M. (1994). Qualitative data analysis: An expanded sourcebook (2nd ed.). Thousand Oaks, CA: Sage Publishing, Inc.

Minium, H. (2016, September 30). Wilder takes to ESPN, warns other coaches: Listen to your players on social issues. The Virginian-Pilot. Retrieved from http://pilotonline.com/sports/college/old-dominion/football/odu-football-players-join-hands-to-address-shootings-in-charlotte/ article 3695ffbd-bf39-5017-b948-f1634ee4e36c.html 
Naraine, M. L., \& Parent, M. M. (2016). "Birds of a feather": An institutional approach to Canadian national sport organizations' social-media use. International Journal of Sport Communication, 9(2), 140-162. https://doi.org/10.1123/ijsc.2016-0010

Newton, C. (2020, March 13). How social networks can do good while we're all trapped indoors. The Verge. Retrieved from https://www.theverge.com/interface/2020/3/13/21176880/ covid-19-quarantine-social-distancing-isolation-loneliness-zoom-fortnite

O'Hallarn, B., \& Shapiro, S. L. (2014). \#NBCFail: A qualitative review of the shared experience as a social movement. First Monday, 19(1), 1. https://doi.org/10.5210/fm.v19i1.4760

O'Hallarn, B., Shapiro, S. L., Hambrick, M. E., Wittkower, D. E., Ridinger, L., \& Morehead, C. A. (2018). Sport, Twitter hashtags, and the public sphere: A qualitative test of the phenomenon through a Curt Schilling case study. Journal of Sport Management, 32(4), 389-400. https://doi. org/10.1123/jsm.2017-0230

Oremus, W. (2015, July 28). Jack Dorsey wants to reinvent Twitter. Slate. Retrieved from http:// www.slate.com/blogs/future_tense/2015/07/28/twitter_q2_earnings_how_jack_dorsey_is_reinventing the company.html

Patton, M. Q. (2002). Qualitative research and evaluation methods. Thousand Oaks, CA: Sage Publishing, Inc.

Pegoraro, A. (2010). Look who's talking — athletes on Twitter: A case study. International Journal of Sport Communication, 3, 501-514. https://doi.org/10.1123/ijsc.3.4.501

Pegoraro, A., Burch, L. M., Frederick, E., \& Vincent, C. (2014). I am not loving it: Examining the hijacking of\# CheersToSochi. International Journal of Sport Management and Marketing, 15(3-4), 163-183. https://doi.org/10.1504/IJSMM.2014.072008

Pegoraro, A., Frederick, E., Burch, L., Sanderson, J., Hambrick, M. E., \& O'Hallarn, B. (2014). Examining social media and the 2014 Sochi Olympic Games. Presentation at the Sport Marketing Association Conference. Philadelphia, PA.

Pitts, B. G. (2001). Sport management at the millennium: A defining moment. Journal of Sport Management, 15(1), 1-9. https://doi.org/10.1123/jsm.15.1.1

Prestridge, S. (2014). A focus on students' use of Twitter-Their interactions with each other, content and interface. Active Learning in Higher Education, 15(2), 101-115. https://doi. org $/ 10.1177 / 1469787414527394$

Rainie, L., \& Wellman, B. (2012). Networked: The new social operating system. Cambridge, MA: MIT Press. https://doi.org/10.7551/mitpress/8358.001.0001

Sanderson, J., \& Browning, B. (2015). From the physical to the social: Twitter as a pedagogical innovation in the sport communication and sport management classroom. Sport Management Education Journal, 9(2), 124-131. https://doi.org/10.1123/SMEJ.2015-0003

Sanderson, J., \& Hambrick, M. E. (2012). Covering the scandal in 140 characters: A case study of Twitter's role in coverage of the Penn State saga. International Journal of Sport Communication 5(4), 384-402. https://doi.org/10.1123/ijsc.5.3.384

Scott, O. K. M., \& Stanway, A. R. (2015). Tweeting the lecture: How social media can increase student engagement in higher education. Sport Management Education Journal, 9(2), 91-101. https://doi.org/10.1123/SMEJ.2014-0038

Shirky, C. (2008). Here comes everybody. New York, NY: Penguin Books.

Smith, L. R., \& Sanderson, J. (2015). I'm going to Instagram it! An analysis of athlete selfpresentation on Instagram. Journal of Broadcasting \& Electronic Media, 59(2), 342-358. https://doi.org/10.1080/08838151.2015.1029125 
Social media use among college students and teens-What's in, what's out and why. (2016, April 26). Modo Labs Team. Retrieved from https://www.modolabs.com/blog-post/social-media-useamong-college-students-and-teens-whats-in-whats-out-and-why/

Strayer, J. F. (2012). How learning in an inverted classroom influences cooperation, innovation and task orientation. Learning Environments Research, 15(2), 171-193. https://oi.org/10.1007/ $\underline{\text { s10984-012-9108-4 }}$

Torres, B. (2019). Job seekers: Social media is even more important than you thought. The Muse. Retrieved from https://www.themuse.com/advice/job-seekers-social-media-is-even-more-important-than-you-thought

Wann, D. L., Royalty, J., \& Roberts, A. (2000). The self-presentation of sport fans: Investigating the importance of team identification and self-esteem. Journal of Sport Behavior, 23(2), 198-206.

Williams, J., \& Chinn, S. J. (2010). Meeting relationship-marketing goals through social media: A conceptual model for sport marketers. International Journal of Sport Communication, 3(4), 422-437. https://doi.org/10.1123/ijsc.3.4.422

Yan, G., Pegoraro, A., \& Watanabe, N. M. (2018). Student-athletes' organization of activism at the University of Missouri: Resource mobilization on Twitter. Journal of Sport Management, 32(1), 24-37. https://doi.org/10.1123/jsm.2017-0031

Zakus, D. H., Malloy, D. C., \& Edwards, A. (2007). Critical and ethical thinking in sport management: Philosophical rationales and examples of methods. Sport Management Review, 10(2), 133-158. https://doi.org/10.1016/S1441-3523(07)70008-6

\section{Appendix}

Class assignment description given to Old Dominion University participants for the \#ODU2ODU study. The Ohio Dominican assignment described the project in identical terms

\section{Department of Human Movement Sciences SMGT 315 Sport Media \& Public Relations Social Media Assignment}

Objective: The goal of this assignment is to get students to consider social media as not merely as something to occupy time, but as a multi-pronged tool that can be used to promote, engage and debate.

Description: This assignment consists of two parts, both of which will be assessed throughout the semester. To participate in this assignment, students will use their Twitter feed throughout the semester as a media engagement tool. The members of this class comprise our online community, and this assignment is a semester-long, multidirectional engagement exercise.

Part 1: Internal engagement. The members of SMGT 315 will interact with the instructor, and with each other, throughout the semester via Twitter. What does that mean? It depends what you make of it. Engagement can come in the form of linking to articles of interest pertinent to the class. It can be striking up debates 
about sporting themes with classmates and with the instructor. It can be garnering attention for your social media site through the creativity and topicality of your posts. This assignment starts right now, and will continue until December.

Part 2: We are excited this semester to have struck a relationship with the "other" ODU. A sport media class at Ohio Dominican University will be our online partners for the semester. This class is now the biggest fans of the Ohio Dominican University Panthers outside of Ohio. For the semester, you will use your Twitter feed to find out about the other ODU, and form online relationships with the students in the sport media class at that university.

What to do: Are you confused? That's totally fine. Start with the Ohio Dominican Athletics website: http://www.ohiodominicanpanthers.com/landing/index. Reach out to your new ODU friends through the shared hashtag for this exercise, \#ODU2ODU. Then become fans and friends of the Panthers this semester. There will be a class of students in Ohio who will be rooting for the Monarchs this fall as well.

ODU2ODU presentation: On Tuesday, Nov. 15 in groups of four, class members will present, in multimedia form, how they have engaged with their friends at Ohio Dominican, and what they have learned about our new sister university. The presentations will be less than 10 minutes, and students are encouraged to make use of technology to demonstrate their interactivity throughout the semester.

Assessment: Each portion of this assignment will be worth 30 points, for a total of 60 , or about one-sixth of your final grade. 